\title{
THE SUSEC SCHOOL PROJECT: INTRODUCING COMPUTER SECURITY TO TEACHERS AND PUPILS
}

\author{
Gunnar Wenngren \\ Linköping University \\ Sweden
}

\begin{abstract}
SUSEC (the Swedish University Information Security Group) is an informal network of computer security officers at Swedish universities and colleges. Its members have a responsibility to ensure that staff and students get a proper education in computer security, copyright matters and netiquette. They became aware that nowadays students usually have a long experience of computer use before they start their university studies. If students are to become responsible computer users they must learn about computer security in the compulsory school system. .
\end{abstract}

SUSEC has conducted a preliminary study of the situation and developed a questionnaire about the degree of technology and security in connection with the introduction of computer use in the school system. It found that most schools give some form of computer use education. Many schools state that they have an IT-strategy and that they have appointed staff responsible for security matters but in most cases this does not create any resulting courses for the pupils. However, single schools, and also some communities, seem to lack sufficient resources and knowledge to maintain an active security policy. All schools expressed a need of educational and information materials.

\section{INTRODUCTION}

SUSEC (the Swedish University Information Security Group) is a very informal network between the computer security officers at the Swedish universities and colleges. This network has, of course, coverage of the whole of Sweden and has among its members all kinds of competencies represented, from experts in hardware, software and networks to administrators and lawyers.

SUSEC has avoided obtaining an official status, which is a great advantage as it is thereby completely independent of government or other official authorities. SUSEC is also totally free from commercial bindings of any kind, which makes the group quite unique. The members of SUSEC join the group on the basis of their own competence and have as such no formal bindings, even to their own university. This independent position has been very much appreciated when SUSEC presented its school project. 
The members of SUSEC have a responsibility not only to maintain a sufficient standard of security for the various computer systems, networks, etc. present in Swedish universities but also to ensure that staff and students get a proper education in computer security, copyright matters and netiquette.

In short: What to do and not to do to ensure that information stored and processed in computers will be available when needed, correct, and not accessed by any unauthorised persons.

\section{PRELIMINARY STUDY}

Up to a couple of years ago our students, in general anyway, started to learn about computers when they started their studies at the university level. During their introduction to computing they were also taught the dos and don'ts of computer security.

SUSEC became, at a very early stage, aware of the rapidly changing situation that emerged from the fact that present day students usually have a long experience of computer use when they start their university studies. Computers are nowadays introduced into the entire school system, sometimes even at nursery school level.

Our conclusion was rather obvious, if our students are to become responsible computer users they must learn about computer security when they start using computers, i.e. in the compulsory school system. To teach them security when they start their university studies will nowadays be much too late as any bad habits would be long established by then.

SUSEC felt it had reason to suspect that the massive introduction of computers at every level of the school system was not accompanied by sufficient education in how the computers should be handled to ensure the safety and security of information handled by the user and others.

SUSEC therefore approached the Foundation for Knowledge and Computer Development on this issue. The Foundation has granted money for a large number of computer and network use projects in the school system. It found the fears of SUSEC to be probably well grounded and granted money for a preliminary study of the situation.

SUSEC developed a questionnaire about the degree of technology and security in connection with the introduction of computer use in the school system. This questionnaire was distributed to the schools and communities that had received grants from the Foundation.

Our intention was to get an opinion about how schools act within the computer area and we found that most schools give some form of computer use education, with or without some 'driver's license'. Many schools state 
that they have an IT-strategy and that they have appointed staff responsible for security matters but in most cases this does not create any resulting courses for the pupils. The emphasis seems to be on knowledge about computers, net surfing and standard software, i.e. word processing (see Table 1 at the end of this paper). Members of SUSEC have also approached a number of schools for follow-up interviews.

One must be aware that the survey only covers a limited number of schools, and that these are in the front line, running development projects in the area. There is reason to believe that the situation at other, less computer active, schools is not any better, rather the opposite.

The result of the survey is nevertheless unambiguous. Single schools, and also some communities, seem to lack sufficient resources and knowledge to maintain an active security policy. All schools that we got in contact with expressed their need of educational and information materials such as general teacher instruction, technical instruction for the staff responsible for computer systems, and information material for pupils and other groups of users.

As a result of this preliminary study SUSEC proposed the project to be continued by:

1. producing an information leaflet, in the first instance, aimed at schools but with a possible wider usage;

2. taking part in the 'IT and learning' conference and exhibition;

3. investigating the need for computer security education material for use in the school system.

\section{PROJECT STAGE 1}

SUSEC had already produced a leaflet for university use with introductory information on computer security. This leaflet was completely revised and was given a more attractive layout. It has been widely spread at schools and universities and has been very well received.

SUSEC took part in the exhibition at 'IT and learning' 29-31 October 1996 with its own booth. Our leaflet was distributed to all visitors to our booth and we 'spread the good word' to about 2,000 people, school leaders, teachers, and technical staff. The overall impression of these contacts was very positive. There seems to be a great demand for all kinds of information on computer security and many visitors asked for practical advice on how networks should be configured, security hardware and software and a lot of other things indicating a large need for the kind of information that SUSEC had felt was missing.

We also made further follow-up interviews at a number of schools and can now conclude that: 
- schools at upper secondary level have in general good access to computers and networks, and those schools with a technical profile seem to have the best resources;

- $\quad$ schools at junior and intermediate level in small communities seem to have the lowest access to computers, etc. and school leaders and teachers at this level also seem to have less individual competence in the field;

- regardless of local status, very few schools/communities have allocated specific resources to the security field: this field is therefore the least developed, with the possible exception for schools with 'fiery spirits' doing voluntary work in their free time;

- the responsibility for security and system management is often trusted to the most knowledgeable person available and that is very often interested older pupils.

SUSEC has been in contact with teacher training colleges aiming at introducing a solid security education there, as these students will be the major link with the future pupils. The colleges must also observe the need for further education of present day teachers in this field. A major survey has been distributed to all teacher colleges.

SUSEC has made an inventory of security risks in connection with the most popular types of servers, with the starting-point of our own tough and hard earned experiences. This inventory and a manual for configuring servers to be at least less vulnerable will be available on the SUSEC web site http://www.susec.sunet.se.

SUSEC has also produced a number of template documents such as security policies, web policies and responsibility obligations. These documents are/will also be available on the web site. The need for information and education material has been investigated and it will be proposed that four 'parcels' be produced.

\section{PROPOSED STAGE 2}

Information and education material will be produced in four 'parcels'.

1. The information leaflet mentioned above will be further revised and completed with an introduction and overhead pictures. This material is very basic, intended for everybody who will work with computers and networks as well as other groups such as parents, politicians and the general public.

2. Parcel 2 is intended for use within the school system and aimed at pupils and other users at public schools. This material is similar to parcel 1 but with a specific school touch.

3. Parcel 3 is intended for the general computer user. It explains common knowledge about computers such as: 
- what it takes to handle your computer and process your information in a safe, secure and responsible way;

- the necessity to take backups and how to handle and store them;

- physical protection against theft, sabotage, fire and other hazards;

- network services such as email, www and gopher, advantages and risks;

- a special emphasis will be made on the use of networks in connection with access control systems and how to choose and handle your password;

- $\quad$ viruses and protection against virus attacks.

This parcel will also deal with ethics, copyright matters, 'law and order' and netiquette.

4. Parcel 4 is intended for technicians and system managers. It will contain qualified information about creating and maintaining a secure computer environment, security organisation and policies as well as incident handling.

Stage 2 is still in preparation and will be finally proposed to the Foundation shortly.

After a preliminary presentation to the Foundation the working group is considering plans to present at least parcels $1-2$ on the Web and/or as an interactive 'game' on $\mathrm{CD}$.

A handbook on information security is also considered either as a complement to the above material or as a solitary product, THE Handbook on information security. SUSEC is, of course, very interested to get in contact with other projects of this kind to exchange experience and for possible co-operation. 

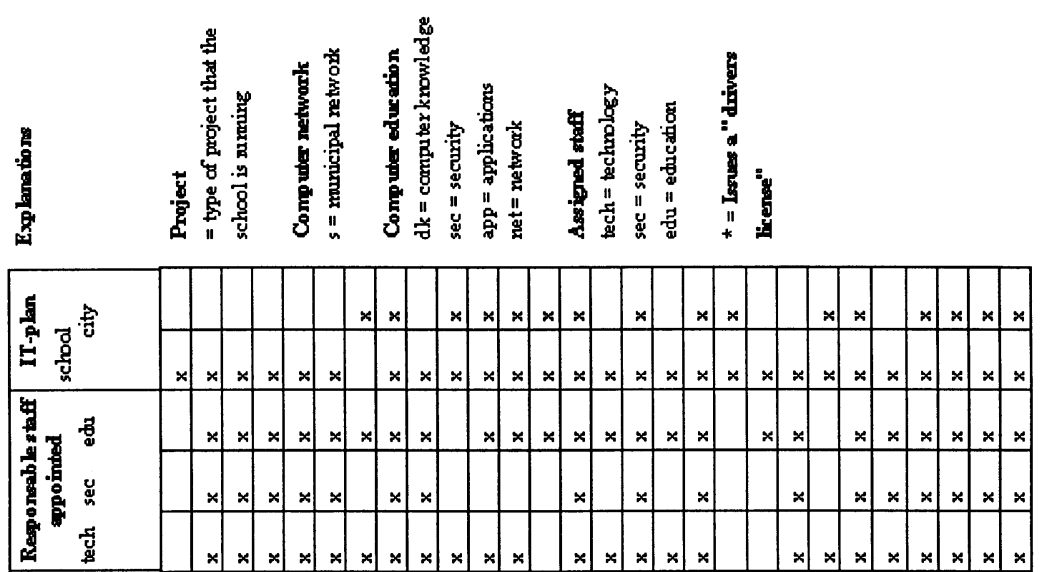

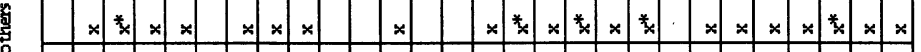

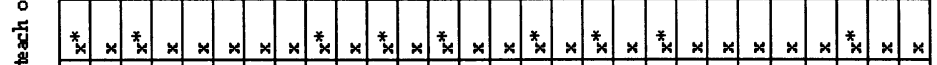

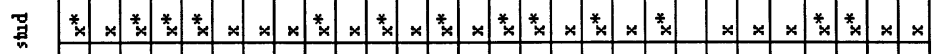

声

$* *$

$\times \times * \times \times * \times \times \times \times *$

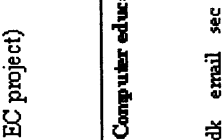

$\times * x \times$

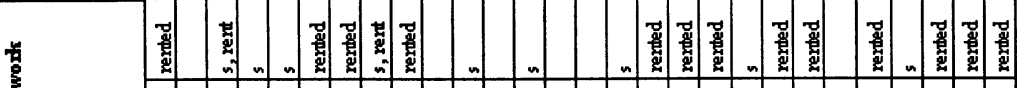

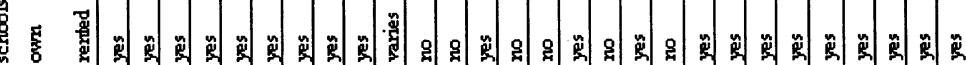
息

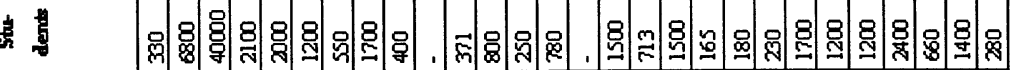

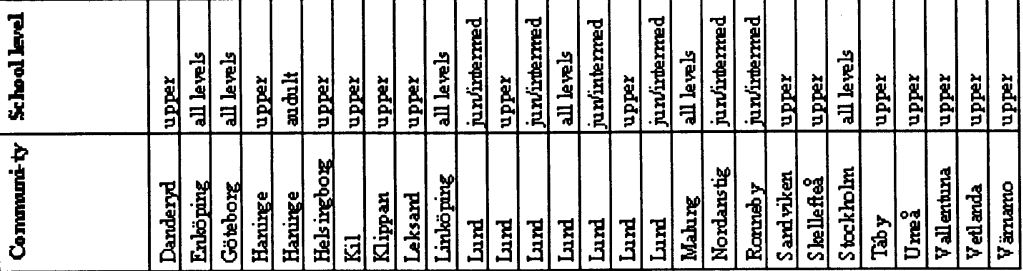

